\title{
Classe política e crise da democracia na crítica de Antonio Gramsci
}

\author{
Alvaro Bianchi* \\ https://orcid.org/0000-0001-5201-5923
}

No início dos anos 1880, a organização dos governos nacionais com base no princípio da representação política obtida por meio de eleições já havia se estendido por boa parte da Europa ocidental e das Américas e, para muitos, assemelhava-se à forma mais adequada, ou ao menos à mais desejada, de governo em todas as naçôes. $\mathrm{O}$ epicentro do qual se espraiava esse movimento político era evidentemente a França, país no qual a Revolução de 1789 parecia ter permitido finalmente a reconciliação dos princípios da soberania popular e da representação política na forma do regime parlamentar. Mas ao mesmo tempo que essa forma de governo se consolidava, um novo gênero de literatura política começava a ganhar vigor e a expandir-se: a análise crítica das democracias parlamentares existentes ${ }^{1}$.

Na Itália, esse gênero ganhou corpo no pensamento político post-Risorgimentale, principalmente depois da expansão do corpo de votantes pela reforma eleitoral de $1882^{2}$. Emergiu então o descontentamento e tornou-se cada vez mais frequente a crítica ao afastamento que o regime parlamentar promoveria entre o "país legal", constituído pelo conjunto de cidadãos portadores de direitos políticos e pelas ins-

1. Apenas para a primeira metade dos anos 1880 e a título de exemplo ver Maine (1885); Prins (1884); Scherer (1884); Syme (1882).

2. A reforma eleitoral permitiu que o número de votantes passasse de 621.896 , em 1879 , cerca de $2,2 \%$ da população, para 2.049.461, 6,9\%, em 1882 (Cammarano, 1999, p. 163). Para a reação do pensamento conservador aos efeitos dessa mudança, ver os comentários de D’Orsi (2011, cap. 2). 
tituições nas quais esses direitos ganhavam sentido, e o "país real”, a grande massa posta à margem da vida política. A crítica provinha de vários lugares do espectro político da época, mas naqueles anos nos quais o movimento socialista dava ainda seus primeiros passos era entre conservadores e liberais de diversos matizes que ela predominava $^{3}$. Escrevendo no próprio ano daquela reforma eleitoral, um desses conservadores, o publicista Pasquale Turiello sintetizou em uma dedicatória a Giustino Fortunato aquela que era a consequência mais evidente do dissídio entre o país legal e o país real: a "discordância crescente entre governo e governados" (Turiello, 1882, p. 5).

Não foram poucos, inclusive o citado Turiello, aqueles que imputaram esse afastamento ao caráter artificial ou imitativo das instituições políticas da Itália unitária, as quais teriam se inspirado no modelo francês já implementado no reino subalpino. Acusava-se recorrentemente essas instituições de serem obra de reformadores sem conhecimento da vida política real e de estarem apoiadas em princípios abstratos, como a liberdade e a igualdade. Tais instituições, afirmava-se, teriam sido construídas ignorando não só a nação realmente existente, como também as tradições políticas da península. $\mathrm{O}$ resultado estaria muito longe das aspirações dos reformadores. $\mathrm{O}$ regime parlamentar, em vez de promover a desejada soberania popular, teria estimulado práticas políticas nocivas, clientelistas e autoritárias.

O diagnóstico pessimista que caracterizava essa literatura completava-se com um discurso político de caráter fortemente normativo. Frequentemente os livros de seus protagonistas encerravam-se com uma proposta de reforma das instituições, como no livro de Marco Minghetti, I partiti politici e la ingerenza loro nella giustizia e nell'amministrazione, cujo capítulo final dedicava-se a inquirir a respeito "dei remedi" necessários para evitar a ingerência dos partidos políticos na administração e no judiciário de modo a garantir a imparcialidade (Minghetti, 1881). De certo modo essa literatura conservadora confluiu mais tarde no clamor por uma diminuição do poder do Parlamento. A reivindicação de Sidney Sonnino, “Torniamo allo Statuto”, anunciada em um conhecidíssimo artigo publicado na revista Nuova Antologia sintetizou de certa maneira esse espírito conservador (ver Un Deputato, 1897).

Interpretações do Risorgimento

Na prisão, Gramsci mostrou-se atento a essa literatura post-Risorgimentale de crítica à democracia parlamentar e àquilo que ela parecia indicar. Não era a qualidade historiográfica dessa literatura aquilo que julgava mais importante, uma vez que

3. Apenas em 1892 foi fundado o Partito dei Lavoratori Italiani, antecessor do Partito Socialista Italiano. 
ela tinha valor predominantemente "de caráter político e ideológico" ( $99, \$ 89$, p. 1153). Ainda assim essa literatura conservadora teria sua relevância, que decorreria não apenas daquilo que ela trazia de informação, mas, principalmente, daquilo que ela revelava do debate político da época, o qual assumia a forma, também, de um debate historiográfico.

Foi nesse parágrafo que Gramsci fez sua primeira referência nos Quaderni ao livro Teorica dei governi e governo parlamentare, escrito pelo jovem Mosca, recém egresso da Facoltà di Giurisprudenzia de Roma. Publicado pela primeira vez em 1884 e republicado em 1925, o livro expressava de maneira fiel os argumentos antiparlamentaristas correntes no millieu conservador ${ }^{4}$. Apresentando-se como um empreendimento científico, alicerçado no método histórico, a Teorica atribuía ao regime parlamentar a propriedade de estimular o monopólio da classe política pela burocracia administrativa, judiciária e militar produzindo "efeitos funestíssimos, pois pouco a pouco separa completamente os governantes dos governados, dá ao últimos indiferença e também o ódio pelos primeiros" (Mosca, 1982 [1884], p. 349).

De acordo com Gramsci, o livro de Mosca era "útil come documento", uma vez que seu autor "termina por trazer à vista muitos aspectos da vida italiana daquele tempo, que de outra maneira não teriam encontrado documentação" ( $\mathrm{Q} 9, \S 89$, p. 1156). Ainda assim, Gramsci reservou palavras ásperas para o livro e o grupo com o qual o identificou. A crítica era duríssima contra o texto da Teorica: "O livro é grosseiro, incerto, escrito apressadamente por um jovem que quer se 'distinguir' em seu tempo com uma atitude extremista e com palavras grosseiras e muitas vezes triviais em um sentido reacionário" ( Q9, \$89, p. 1135)5.

Ao lado do livro de Mosca, e representando um mesmo movimento cultural, Gramsci citou as obras de Pasquale Turiello, Leone Carpi, Luigi Zini, Giorgio Arcoleo, Marco Minghetti, além de artigos publicados por Pasquale Villari, Ruggero

4. Embora o livro não tenha sido encontrado entre aqueles que Gramsci deixou no cárcere, é muito provável que ele tenha lido a segunda edição na prisão e a tivesse em mãos quando escreveu a nota. Três indícios corroboram essa hipótese: (a) várias referências bibliográficas citadas nos Quaderni coincidem com aquelas apontadas por Mosca em sua obra (comparar as referências citadas em Q 9, \$ 89, p. 1154; e Mosca, 1982 [1884], p. 487); (b) nos Quaderni é feita menção às mudanças no texto original que Mosca teria introduzido na segunda edição; c) em vez de datar a publicação da primeira edição em 1884 informação muito fácil de encontrar se a tivesse em mãos, afirma que ela é de 1883, seguindo a data que consta no prefácio republicado em 1925.

5. As palavras de Mosca para a democracia parlamentar eram, de fato, duras e ásperas e o diagnóstico que desenhou, extremamente desfavorável: "É também o sistema em que a covardia moral, a falta de qualquer sentimento de justiça, o mal, a intriga, que são precisamente as qualidades que levam os povos e Estados a se arruinar, encontram o seu melhor jogo, mais levam adiante seus seguidores, e mais eles tendem a se destacar e desenvolver" (Mosca, 1982 [1884], pp. 486-487). 
Bonghi e Luigi Palma ${ }^{6}$. Produzida por conservadores, essa literatura "irascível, biliosa, acrimoniosa, sem elementos construtivos" seria uma reação à "diminuída importância na vida estatal dos grandes proprietários de terra e da aristocracia" depois que a Sinistra liderada por Agostino Depretis chegou ao poder em 1876. O pensamento político desses autores seria, em grande medida, "uma consequência da queda da Destra, do advento ao poder da Sinistra e das inovações 'de fato' introduzidas no regime parlamentar. Em grande medida são lamentações, recriminações, juízos pessimistas e catastróficos sobre a situação italiana” ( $Q 9, \$ 89$, p. 1154).

As críticas de Gramsci tinham um sentido fortemente político. Aquilo que essa literatura documentava era múltiplo. Eram dois os movimentos político-intelectuais com os quais Gramsci estava lidando, ambos muito vinculados à história dos intelectuais e das ideias na Itália. O primeiro era daquela literatura do final do século XIX e do início do século xx, na qual os ressentimentos da Destra derrotada pareciam aflorar. Mas havia outro movimento, talvez mais importante: aquele no qual essa literatura era reapropriada e revalorizada no debate político a partir do imediato pré-guerra, quando a crise da democracia liberal assumia contornos mais fortes.

Sujeitos dessa reapropriação foram primeiro as correntes moderadas, nacionalistas e, mais tarde, as fascistas. A difusão das ideias de Mosca convergia com o surgimento de um pensamento aristocrático, inspirado na livre leitura que Gabriele D’Annunzio promoveu de Friedrich Nieztsche no final do século xIX e inicio do século xx. Gramsci esteve atento a esses movimentos e comentou a revalorização da obra de Pasquale Turiello pela revista La Voce, dirigida por Giuseppe Prezzolini, provavelmente uma referência ao tardio e sóbrio comentário de Alberto Caroncini $(1912)^{7}$. Por essa razão, considerava que a reedição da Teorica de Mosca em 1925 era "um dos tantos episódios da inconsciência e do diletantismo dos liberais" ( $Q$ $9, \S 89$, p. 1155).

A acolhida dessas obras ia além e chegava até mesmo aos liberais, como Benedetto Croce, como se pode verificar nas referências a Mosca e Turiello em sua Storia d'Italia, citadas por Gramsci (ver Croce, 2004 [1928], p. 102 e Q 9, \$89, p. 1154), ou na elogiosa resenha que La Critica publicou da segunda edição de Elementi di scienza politica (Croce, 1923). Acrescente-se a apropriação das ideias mosquianas por Piero Gobetti no jornal La Rivoluzione Liberale e a resenha favorável que este

6. Como visto, os livros de Turiello, Carpi, Zini, Arcoleo e Minghetti são citados com base nas referências do próprio Mosca que os considerava suas fontes de inspiração.

7. Acrescente-se que já em 1903, nas páginas da revista Il Regno, o mesmo Prezzolini havia indicado Gaetano Mosca e Vilfredo Pareto como suas inspirações científicas e filosóficas: "podemos nos voltar para Gaetano Mosca e Vilfredo Pareto, que nos treinaram em suas obras para justificar cientificamente e filosoficamente nosso trabalho prático" (Prezzolini, 1960, p. 455). 
publicou a respeito dessa mesma edição referindo-se a Mosca de maneira insuperável como "Un conservatore galantuomo" (Gobetti, 1924).

Gramsci demonstrava estar vigilante com relação a esse movimento político-intelectual e seus efeitos na luta política da época. Prestava desse modo atenção a uma apropriação da crítica elitista - liberal ou conservadora - da democracia por um pensamento oligárquico. Essa apropriação encerrava um perigo ao qual era necessário estar atento: a dissolução do liberalismo e do conservadorismo no interior de uma crítica meramente reacionária ou mesmo despótica do regime parlamentar?

\section{Classe política e intelectuais}

O movimento que Gramsci promoveu nos Quaderni ia em direção oposta à dessa crítica oligárquica, reacionária e despótica e procurava traduzir a historiografia e a ciência política dos elitistas na filosofia da práxis. Notável, nesse sentido, foi o uso cauteloso que promoveu da noção de classe política, presente na obra de Gaetano Mosca. Em sua Teorica dei governi e governo parlamentare, o jovem palermitano, contrariando definição universalmente aceita à época, havia escrito que: “Os governantes, isto é, aqueles que têm em mãos e exercitam os poderes públicos, são sempre uma minoria, e que, abaixo deles, há uma grande classe de pessoas, que nunca participam de modo algum no governo, elas só fazem subi-lo, as quais podem ser chamados de governados" (Mosca, 1982 [1884], p. 203).

Essa distinção entre governantes e governados, comum na literatura daqueles anos, era assim radicalizada e apreendida como fato "constantíssimo e general" por meio da observação da sociedade, constituindo-se em chave de abóboda de uma nascente ciência política. Em Mosca essa distinção tornava-se estável no tempo, apresentando-se como característica essencial de toda forma de governo. O conceito que permitiria explicar essa característica e organizar o estudo das formas de governo, em particular da forma atual do governo italiano, era o conceito de classe política. De acordo com Mosca,

Em todos os tempos e em todos os lugares, tudo o que no governo é uma parte dispositiva, um exercício de autoridade e implica comando e responsabilidade é sempre a atribuição de uma classe especial, cujos elementos de formação, de acordo com o século e o país, podem

8. A influência das ideias de Gaetano Mosca sobre La Rivoluzione Liberale era notável. No próprio manifesto do jornal afirma-se como um dos objetivos do jornal a pesquisa histórica "a ausência de uma classe dirigente como classe política” (Gobetti, 1922, p. 1).

9. Gramsci estabeleceu rapidamente e sem aprofundar essa distinção entre crítica de "origem oligárquica” ao regime parlamentar e a crítica dos elitistas (Q 13, §30, p. 1625). 
variar muito, é verdade, mas também, de qualquer modo que seja composta, sempre se forma diante da massa dos governados, à qual se impõe uma pequena minoria. Esta classe especial nós, de agora em diante, chamaremos a classe política (Mosca, 1982 [1884], p. 207) ${ }^{10}$.

Gramsci tinha suas ressalvas ao enunciado por Mosca do conceito de classe política e procurou explicitá-las no texto. Sobre a exposição do conceito na Teorica, escreveu: “classe politica', cuja afirmação se tornará centro de todos os escritos de ciência política de Mosca, é de extrema fragilidade e não é fundamentado nem justificado teoricamente" ( $Q 9, \$ 89$, p. 1156) ${ }^{11}$. O juízo negativo a respeito do conceito de classe política se estendeu nos comentários dirigidos aos Elementi di scienza politica, de Gaetano Mosca, obra escrita em "dois momentos típicos da histórica político-social italiana, em 1895 e 1923, enquanto a classe política se desintegra e não consegue encontrar um terreno sólido de organização" (Q 8, § 52, p. 972) ${ }^{12}$. De acordo com Gramsci:

[...] nem sequer se compreende exatamente o que Mosca entende precisamente por classe política, tão ondulada e elástica è a noção. Parece abraçar todas as classes possuidoras, toda a classe média; mas qual então a função da classe alta? Em outros momentos parece referir-se apenas a uma aristocracia política ao "pessoal político" de um Estado e, ainda, àquela parte que opera "livremente" no sistema representativo, isto é, excluindo a burocracia mesmo em sua camada superior, a qual para Mosca deve ser controlada e liderada pela classe política (Q 8, §52, p. 972).

A principal lacuna da reflexão mosquiana nesse livro estaria em que "não enfrenta a questão do partido como um todo" (Q 8, \$ 52, p. 972). A ausência de uma reflexão desenvolvida sobre os partidos políticos impediria Mosca de compreender os processos de formação da classe política e de mudança social, ou seja, da criação de "um novo nível de civilização". As observações sobre o conceito de classe política

10. Sobre o conceito de classe política na Teorica, ver, em especial, Albertoni (1985, cap. III e IV).

11. Mosca oscilou na denominação: utilizará como sinônimos de classe política expressões como "classe governante", “classe dirigente", "classe dominatrice”, "classe superiore”, “classe elevata”, "governanti”, "elementi dominatori” " "minoranzza organizata”. Ver o levantamento feito por Giorgio Sola no texto da Teorica (Mosca, 1982 [1884], p. 207). Sobre essas oscilações e as possíveis diferenças entre os termos, ver também Filippini (2015, pp. 199-200)

12. A primeira edição de Elementi di scienza politica foi publicada por Gaetano Mosca em 1896. Uma nova edição aparece em 1923, na qual seu autor acrescentou uma segunda parte completamente inédita. Embora o livro não esteja entre aqueles que Gramsci deixou na prisão é provável que tivesse em mãos esta segunda edição, como se infere da longa citação que faz de um texto de Guglielmo Ferrero com base na obra de Mosca ( $\mathrm{Q} 8, \$ 36$, p. 963). Os momentos típicos aos quais Gramsci faz referência são marcados pela derrota italiana na batalha de Adua, que revelou a crise do regime liberal (1896), e a marcha fascista sobre Roma (1923), quando essa crise encontrou uma solução reacionária. 
de Mosca eram fortemente vinculadas nessa nota à noção de moderno Príncipe e ao caráter de educador da classe política que este teria. Mas o texto é desordenado e observações desconexas sobre o moderno Príncipe, a revolução permanente, a guerra de posição, a guerra de movimento e as ideologias aparecem justapostas ${ }^{13}$.

Apesar de suas ressalvas, Gramsci considerou que o conceito mosquiano de classe política poderia ser útil para aquela análise histórica dos intelectuais italianos na qual estava trabalhando. Com esse propósito, registrou uma rápida, mas importante, observação em uma nota dedicada a essa análise histórica e justamente intitulada "Note sparse e appuntiper una storia degli intellettuali italiani": "A assim denominada 'classe política' de Mosca não é outra coisa que a categoria intelectual do grupo social dominante" ( $\mathrm{Q} 8, \$ 24, \mathrm{p} .956)^{14}$. Nessa mesma nota, considerou que o conceito de classe política poderia ser avizinhado ao conceito de élite de Pareto, que também seria uma tentativa de interpretar o fenômeno histórico dos intelectuais e sua função na vida social e estatal.

Como visto, Gramsci havia lido tanto a Teorica como os Elementi de Mosca e certamente teve esses livros na prisão. Seu conhecimento das ideias de Vilfredo Pareto era, entretanto, menor, mas há alguns indícios em seus artigos juvenis de que pode ter lido o Tratatto di Sociologia, obra à qual se referiu de maneira indireta, porém, precisa, em um artigo publicado no jornal Avanti! no ano seguinte ao lançamento desse livro $^{15}$. As ideias de Mosca e Pareto, entretanto, eram correntes nos meios intelectuais da Torino do início do século Xx, cidade pela qual ambos passaram e cuja cultura marcaram de modo notável ${ }^{16}$. Mas sua influência ia muito além da cidade e pode-se dizer, sem medo de errar, que nos primeiros anos do século XX a teoria elitista desses autores havia encontrado forte difusão, consolidando-se no léxico político da época.

Embora Gramsci tenha procurado aproximar os conceitos de classe política e de elites, eles não são idênticos entre si. Albertoni destacou que enquanto o conceito mosquiano de classe política remetia a um âmbito político-estatal, o conceito paretiano de elites era apresentado em termos essencialmente sociais (Albertoni, 1985, p. 267). Gramsci parecia estar ciente disso quando afirmou que o conceito mosquiano

13. Na segunda versão o texto foi depurado, concentrando-se no argumento mosquiano. Mas a crítica à ausência de uma reflexão sobre os partidos políticos foi mantida como ponto principal da crítica $(\mathrm{Q}$ $13, \S 16$, p. 1565$)$.

14. Essa observação inseria-se no contexto das pesquisas anunciadas já em uma carta a Tania de 19 de março de 1927 (L, p. 55-56).

15. "Os sociólogos dividem os eventos em duas grandes categorias: eventos lógicos, eventos não-lógicos. Eventos lógicos: aqueles que podem ser previstos; não lógicos: aqueles imprevisíveis” (Gramsci, 1982, p. 51. "La Tegola”. Avanti!, a. Xxi, n. 54, 23 feb. 1917).

16. Sobre a presença e influência de Mosca e Pareto em Torino, ver D’Orsi (2002, cap. II e III). 
de classe política dizia respeito exclusivamente aos grupos dominantes ${ }^{17}$. Os usos que Gramsci fez nos Quaderni dos conceitos de élites e classe política é revelador dessas diferenças. Gramsci utilizou o conceito de élites em um sentido quase neutro, muitas vezes adjetivando-o para torná-lo mais delimitado. Escreveu assim a respeito de uma "élite intelectual, mas especialmente moral", "élite de intelectuais" ou, simplesmente, “élite intelectual” (Q 4, \$ 49; p. 480, Q 12, \$1, p. 1525; Q 14, § 18, p. 1676; Q 19, § 24, p. 2027); de "élite de ricos e de moças" ( 4 4, \$ 49, p. 483); de "élites de jovens escolhidos por concurso ou indicados por instituições privadas idôneas sob a sua responsabilidade" ( $\mathrm{Q} 4, \$ 49$, p. 485); de "élite internacional" (Q 6, \$62, p.731); e de uma "élite-aristocracia-vanguarda" (Q 6, \$79, p. 750). A ambiguidade do conceito permitia a Gramsci utilizá-lo, ainda, para referir-se obliquamente aos grupos intelectuais das classes subalternas, como no $\$ 79$ do Quaderno 6, com a rubrica "Riviste tipo".

Por sua vez, apesar das reiteradas ressalvas, "classe política", com ou sem aspas, aparece como uma importante, embora infrequente, noção nos Quaderni. O uso das aspas remete geralmente ao conceito no interior da obra mosquiana, e desse modo ele aparecia na maioria das notas nas quais Gramsci se dedicou a comentar a Teorica e os Elementi. Predomina o uso sem aspas quando esta é uma noção incorporada por Gramsci a seu próprio léxico e utilizada para designar os grupos intelectuais e dirigentes das classes dominantes. É nesse último sentido, certamente mais rico em termos analíticos, que Gramsci se refere, por exemplo, à "elaboração que tem lugar na classe política piemontesa durante o império napoleônico" ( $\mathrm{Q} 6, \S 70, \mathrm{p} .737$ ) ou "à classe politica italiana" ( $\mathrm{Q} 9, \S 108, \mathrm{p} .1172)$. Ou ainda o sugestivo $₫ 48$ do Quaderno 8, no qual distingue a grande política, voltada em termos maquiavelianos para a conquista e manutenção do Estado, e a "pequena política às questôes parciais e diárias que são colocadas dentro de uma estrutura já estabelecida para as lutas de proeminência entre as diferentes frações da mesma classe política” (Q, 8, §48, p. 970).

Pode-se dizer, assim, que enquanto Gramsci circunscreve o conceito de classe política ao aparelho governativo, à sociedade política, utiliza a noção de élites para nomear grupos que se encontram predominantemente no âmbito da sociedade civil, nos aparelhos privados de hegemonia. Talvez por essa razão prefira utilizar a noção de classe dirigente, que permite identificar grupos que tem lugar nessas duas dimensões, ou seja, no "Estado em seu sentido orgânico e mais amplo (Estado propriamente dito e sociedade civil)” ( $\mathrm{Q} 6, \S 87, \mathrm{p} .763)$. O uso da noção de classe dirigente pode ser encontrado já nos escritos pré-carcerários e culminava nas Teses de Lyon e na densa

17. O conceito mosquiano de classe politica corresponderia não ao conceito de élite tout court tal como aparece na obra de Pareto e sim ao que o professor de Lausanne chamava de "classe eletta di governo" (Pareto, 1988 [1923], §2056, p. 1955). 
análise das classes dirigentes italianas que ali tinha lugar ${ }^{18}$. A expressão reaparecerá no Primo quaderno, nas notas destinadas à análise do Risorgimento italiano, no qual é apresentada uma teoria da hegemonia, em particular no $\$ 44$ do Quaderno 19. Essa primeira aparição já indica fortemente que a noção de classe dirigente só adquire pleno sentido no texto gramsciano mais maduro quando inserida no âmbito dessa teorização sobre as formas de dominação e direção na vida estatal ${ }^{19}$.

\section{Partidos políticos e crise da democracia}

A noção de classe dirigente é central para compreender a análise gramsciana da crise do regime parlamentar. $\mathrm{O}$ diálogo com as teorias elitistas era intenso neste ponto. Ao analisar o conjunto daquelas "Interpretazioni del Risorgimento italiano", em particular as do "gruppo Mosca-Turiello", Gramsci considerou, no Quaderno 9, que aquele tipo de literatura prosperava em situações de crise, uma crise que essa literatura não era capaz de compreender. Sua observação a respeito é importante para um melhor entendimento do modo como ele via a crise:

Percebe-se que essas interpretações florescem nos períodos mais característicos da crise político-social e são tentativas para provocar uma reorganização das forças políticas existentes, estimular novas correntes intelectuais em antigos organismos partidários ou exalar suspiros e gemidos de desespero e negro pessimismo (Q9, \$89, pp. 1153-1154).

Nota-se que tal literatura floresce nos períodos mais característicos da crise político-social, quando a separação entre governantes e governados se torna mais grave e parece anunciar eventos catastróficos para a vida nacional; o pânico se difunde entre certos grupos intelectuais

18. Por exemplo: "O primeiro período de vida do Estado italiano (1870-1890) é o da sua maior debilidade. As duas partes das quais a classe dominante é composta, os intelectuais burgueses de um lado e os capitalistas de outro, estão unidas no propósito de manter a unidade, mas divididas na forma a ser dada ao Estado unitário. Falta entre elas uma homogeneidade positiva. Os problemas que o Estado propõe são limitados; ao contrário, dizem respeito à forma que a substância da dominação política da burguesia; acima de tudo, o problema do equilíbrio, que é um problema de pura preservação. A consciência da necessidade de alargar a base das classes que governam o estado ocorre apenas com o início do 'transformismo"' (Gramsci, 1987, p. 493).

19. Ver, por exemplo: "O critério histórico-político sobre o qual se deve fundar a própria pesquisa é o seguinte: que uma classe é dominante de duas maneiras, quer dizer, é 'dirigente' e 'dominante'. É dirigente das classes aliadas, é dominante das classes adversárias. Por isso uma classe antes mesmo de chegar ao poder pode ser 'dirigente' (e deve sê-lo): quando está no poder torna-se dominante, mas continua a ser, também, 'dirigente'. [...] Pode-se e se deve ser uma 'hegemonia política' mesmo antes de ir ao Governo e não se precisa contar somente com o poder e a força material que este poder dá para exercer a direção ou hegemonia política" ( $\mathrm{Q} 1, \S 44, \mathrm{p} .41)$. 
mais sensíveis e se multiplicam as tentativas para provocar uma reorganização das forças políticas existentes, estimular novas correntes intelectuais nos extenuados e pouco consistentes organismos partidários ou exalar suspiros e gemidos de desespero e negro pessimismo ( 19 , $\$ 5$, p. 1975)

A segunda versão desse texto permite iluminar um ponto importante e persistente da reflexão gramsciana sobre a "crise político-social". Esta é interpretada como o resultado do agravamento da separação entre "governantes e governados”. As palavras destacadas eram ainda as que organizavam o léxico dos elitistas. Embora Gramsci criticasse aquela literatura que insistia na tese segundo a qual "o marasmo no qual se encontra o país" teria sido provocado exclusivamente pelo "regime parlamentar (que talvez só torne público aquilo que antes permanecia escondido)”20, a explicação que o próprio Gramsci construía encontrava-se fortemente marcada não apenas pelo léxico, como também, por uma ideia que é possível encontrar na Teorica de Mosca: a crise teria sido uma consequência da "debilidade geral da classe dirigente e da grande miséria do país" (Q9, \$89, pp. 1154-1155).

Essa maneira de conceber a crise foi exposta de maneira mais detalhada, como era de se esperar, no Quaderno 13. Primeiro no $\$ 23$, intitulado “Osservazioni su alcuni aspetti della struttura dei partiti politici nei periodi di crisi organica", uma nota que julgou pertinente conectar explicitamente com o importantíssimo $\$ 17$, “Analisi delle situazioni: rapporti di forza”. Nessa nova sede foram reagrupados textos presentes anteriormente nos quaderni 4 ( $\$ \$ 66$ e 69, redigidos em novembro de 1930), 7 ( $\$$ 77 , escrito em dezembro de 1931$)$ e 9 ( $\$ 22$, de maio de 1932 , e $\$ 40$, de junho de 1932), dedicados originalmente ao estudo do "elemento militar na política", dos "partidos políticos" e da "burocracia”. Espalhadas no tempo, com diverso conteúdo e carentes de fontes explícitas, essas notas inscritas nos quaderni miscelani não formam originalmente um todo orgânico. Foi apenas no Quaderno 13 e no processo de reelaboração que ganharam uma unidade temática mais forte.

20. Embora essa crítica não fosse completamente justa no caso de Mosca, o qual via a crise como resultado da estreiteza do processo de seleção da classe política, ela era pertinente para boa parte da literatura post-risorgimentale produzida pela Destra, e em particular para o livro de Pasquale Turiello também citado por Gramsci como representante dessa corrente. Na carta de apresentação que Turiello endereçou a Fortunato, afirmou que seu livro "pode se tornar o conteúdo de qualquer um dos partidos políticos presentes, embora eu ache que aquele que caiu em 1876 poderia revivê-lo mais facilmente" (Turiello, 1882, p. 8). Esse autor era bastante explícito a respeito do caráter artificial e imitativo das instituições políticas italianas. Sobre a importação das instituições, afirmou: "nossa legislação, tanto em tempos de plenos poderes ministeriais, como por meio de discussão parlamentar, foi quase completa e sumariamente imitada dos modelos belgas e franceses, alguns deles já adotados anteriormente pelo reino subalpino" (Turiello, 1882, pp. 13-14). 
Como o próprio título anuncia, o $\$ 23$ do Quaderno 13 tem por objeto a análise da crise dos partidos políticos. Colocava-se assim, no centro da reflexão aquilo que Gramsci havia identificado como uma lacuna no conceito de "classe política" de Gaetano Mosca. O texto, entretanto, não reproduz uma análise formal da estrutura interna das agremiações políticas. Seu objeto de estudo era aquilo que hoje chamaríamos de sistema partidário, o conjunto articulado dos partidos em uma dada unidade nacional. Com esse propósito, o parágrafo iniciava com uma afirmação generalizante a respeito da relação entre representantes e representados, a qual, de certo modo, sintetizava a trajetória dos partidos parlamentares europeus no imediato pós-guerra: "Em um certo ponto de sua vida histórica, os grupos sociais se separam de seus partidos tradicionais, isto é, os partidos tradicionais, na forma organizacional dada, com aqueles certos homens que os constituem, os representam e os dirigem, não são mais reconhecidos como expressão de sua classe ou fração de classe" ( $\mathrm{Q} 13, \S 23$, p. 1602).

Gramsci retomava aqui uma ideia já presente na literatura do final do século XIX: o que caracterizava a crise política era o afastamento entre representantes e representados, dirigentes e dirigidos, governantes e governados (ver o já citado Q 19 , $\S 15$, p. 1975). A crise subverteria o funcionamento normal do regime parlamentar, no qual a "democracia política tende a fazer coincidir governantes e governados (no sentido de governo com o consenso dos governados)" (Q12, \$12, p. 1547 $)^{21}$. Nessas situações nas quais a coincidência deixava de existir reforçava-se "a posição relativa do poder da burocracia (civil e militar), da alta finança, da Igreja e em geral de todos os organismos relativamente independentes das flutuações da opinião pública." ( $\mathrm{Q}$ $13, \S 23$, p. 1603). Descrevia-se, assim, o processo de autonomização da sociedade política em relação à sociedade civil.

Essa crise, que se manifesta primeiro no interior dos partidos políticos entre dirigentes e dirigidos, se expressaria também "em todo o organismo estatal", contaminando toda a vida politica nacional. O conteúdo dessa crise, segundo Gramsci, "é a crise de hegemonia da classe dirigente". Na literatura da época, principalmente naquela de corte elitista, na qual se destacava Gaetano Mosca, esse fenômeno recebia o nome de "crise de autoridade"22. O próprio Gramsci, escrevendo em 1921 afirmou que a "crise geral italiana é crise das classes médias, é crise do princípio de autoridade nos comandos sociais subalternos, que precisamente constituem o máximo da es-

21. Ver as observações a respeito dessa passagem em Vacca (2017, p. 190).

22. Comentando a elevação da prosperidade material, da cultura e dos recursos intelectuais da sociedade italiana na Itália liberal, Mosca escreveu, por exemplo, que esta era acompanhada por "una lenta decomposizione del principio d'ordine e d'autorità' (Mosca, 1982 [1884], p. 514). 
trutura burguesa do Estado" (Gramsci, 1966, p. 146) ${ }^{23}$. Nos Quaderni, entretanto, aquilo que antes recebia o nome de "crise do princípio de autoridade" passou a ser compreendido de maneira mais abrangente e precisa como uma "crise de hegemonia, ou crise do Estado em seu conjunto" (Q 13, §23, p. 1603).

O texto de Gramsci demonstra preocupação com os rumos que uma crise política poderia tomar. A situação imediata criada pela crise poderia tornar-se "delicada e perigosa”, alertava no $\$ 23$. O aviso tinha em mente a solução particular que a crise de hegemonia havia encontrado na Itália com a ascensão do fascismo. Na crise, abria-se o campo "às soluções de força, à atividade de potências obscuras representadas pelos homens providenciais ou carismáticos” ( $\mathrm{Q} 13, \S 23$, p. 1603). A solução "normal" da crise era outra, do ponto de vista da "classe dirigente tradicional". Ela possuía recursos maiores do que aqueles disponíveis pelas classes subalternas. $\mathrm{O}$ pessoal dirigente dessas classes tradicionais era numeroso e treinado e mesmo que fosse necessário fazer sacrifícios para manter o poder poderia com um custo menor "esmagar o adversário e dispersar o pessoal dirigente" ( $\mathrm{Q} 13, \S 23$, p. 1603). Desse modo poderia passar-se rapidamente à direção de muitos partidos "sob a bandeira de um único partido que melhor representa e resume as necessidades de toda a classe" ( $\mathrm{Q} 13, \S 23$, p. 1604).

Essa solução na qual ocorre "a fusão de todo um grupo social sob uma única direção que é considerada a única capaz de resolver um problema existencial dominante e afastar um perigo mortal" era considerada "um fenômeno orgânico e normal", mas ela teria lugar apenas quando existisse uma relação de forças francamente favorável às classes dirigentes tradicionais $(\mathrm{Q} 13, \S 6, \mathrm{p} .1604)$. A crise encontraria outra solução quando essa relação de forças não existisse, quando predominasse um "equilíbrio estático" entre as classes, ou seja, quando "nenhum grupo, nem o conservador nem o progressivo, tem a força necessária para a vitória e mesmo o grupo conservador também precisa de um mestre". Nessa situação na qual o "fenômeno orgânico e normal" não é possível surgem as condições para a afirmação de um "chefe carismático".

Gramsci já havia escrito a respeito da noção de capo carismático em uma nota do Quaderno 2, em um parágrafo destinado a discutir a obra de outro importante expoente do pensamento elitista, Robert Michels. O parágrafo é revelador do método de trabalho de Gramsci. A primeira parte do texto, escrita provavelmente em fevereiro de 1929, consiste de uma longa paráfrase de um artigo publicado por Michels na revista Mercure de France com algumas observações de Gramsci interpoladas entre parênteses ${ }^{24}$. A redação desse parágrafo foi retomada mais tarde, entre

23. Trata-se de artigo não assinado, publicado em L'Ordine Nuovo, 23 apr. 1921, a. I, n. 113.

24. Ver Michels (1927). A maioria das referências citadas nesse parágrafo encontrava-se no texto do pró- 
agosto e setembro de 1930, e no final dela o autor expôs um juízo geral sobre a obra do sociólogo alemão ${ }^{25}$.

De modo geral, nesse texto as ideias de Michels sobre os partidos políticos eram consideradas bastante confusas e esquemáticas, mas “interessantes como uma coleção de material bruto e observações empíricas e díspares” ( Q 2, §75, p. 237), um juízo similar àquele expresso a respeito de Mosca. Porém, há alguns indícios de que Gramsci havia planejado aprofundar seus estudos sobre Michels, mas isso não ocorreu, as referências são apenas ocasionais e esse parágrafo não recebeu uma segunda redação ${ }^{26}$. As observações de Michels sobre o capo carismático forneceram, entretanto, um pretexto para que Gramsci refletisse sobre o tema. Benito Mussolini era citado explicitamente no texto de Michels e, embora Gramsci considerasse que as observações do sociólogo alemão sobre o caso italiano fossem inexatas, elas lhe permitiram mobilizar diretamente a noção de carisma para a análise do fascismo (Sgambatti, 1977, p. 611).

Gramsci suspeitava, entretanto, que o sociólogo alemão radicado na Itália não fosse o portador de uma reflexão original e que o conceito de capo carismático já estivesse presente na obra de Max Weber, planejando cotejar a obra deste com o livro de sociologia política publicado por Michels em 1927 (Q2, \$75, p. 231)27. No sentido atribuído por Michels, escreveu Gramsci, o carisma coincidiria sempre com "uma fase primitiva dos partidos de massa", na qual "a doutrina se apresenta às massas como algo nebuloso e incoerente, que precisa de um papa infalível para ser interpretada e adaptada às circunstâncias." (Q 2, \$75, p. 233). Os partidos “carismáticos”, por sua vez, seriam "agrupamentos em torno de certas personalidades, com programas rudi-

prio Michels. As exceções estão na segunda parte da nota, redigida mais de um ano depois: uma carta de Sorel a Croce, publicada na revista La Critica de 20 de setembro de 1929, na qual uma brochura do sociólogo alemão era criticada, e de um conjunto de cartas de Sorel a Michels, publicadas pela revista Nuovi Studi di Diritto, Economia e Politica de setembro-outubro de 1929.

25. Sobre a composição do Quaderno 2 e dessa nota em particular, ver Francioni (2009). As datas de composição das duas partes foram sugeridas por Cospito (2011).

26. Nesse mesmo parágrafo, por exemplo, Gramsci escreveu: "La bibliografia degli scritti del Michels si può sempre ricostruire dai suoi stessi scritti, perché egli si cita abbondantemente. La ricerca può incominciare dai libri che ho già" ( $\mathrm{Q} 2, \S 75, \mathrm{p} .237$ ). Sobre as fontes disponíveis por Gramsci para esse estudo, ver a minuciosa pesquisa de Bettoni (1984, pp. 212-218)

27. Trata-se do Corso di Sociologia Politica, publicado em Milão naquele ano (Michels, 1927). Gramsci possuia na prisão o livro de Michels sobre os partidos politicos e conhecia o Corso di Sociologia Politica, embora seja improvável que o tenha lido. De Weber citou repetidamente Parlamento e governo nel nuovo ordinamento della Germania, publicada em 1919 pela editora Laterza. Mas o planejado estudo comparativo teria sido possível apenas a partir de 1934, quando recebeu no cárcere uma antologia de textos organizados por Michels, entre os quais estava a seção v do capítulo vin de Wirtschaft und Geselschaft, de Max Weber, publicada com o título "Il potere carismatico e la sua trasformazione" (Filippini, 2017, p. 117). 
mentares; a base desses partidos é a fé e autoridade de apenas um" ( $Q 2, \$ 75, \mathrm{p} .234)$. Gramsci considerava, entretanto, que essa categoria de classificação não corresponderia a nenhum partido realmente existente. Criticava a ideia de Michels segundo a qual os partidos carismáticos não teriam um programa definido. De acordo com o sardo, personalidades "mais ou menos excepcionais" seriam sempre a expressão de interesses. O que permitiria a emergência de um capo carismático não seria o caráter rudimentar do partido e sim uma particular relação de forças entre as classes: "em certos momentos de 'anarquia permanente' devido ao equilíbrio estático das forças em luta, um homem representa a 'ordem', isto é a ruptura com meios excepcionais do equilíbrio mortal e em torno dele se reagrupam os amedrontados, as 'ovelhas hidrofóbicas' da pequena burguesia” (Q2, \$75, p. 234).

Gramsci parece diferenciar aqui uma crise decorrente do "equilíbrio estático das forças em luta", a qual se expressaria na dificuldade de formar um governo, de uma crise da forma Estado, aquilo que nesse parágrafo chama de "crises constitucionais". Essa distinção é importante. Nem toda crise política ou parlamentar, é ou se torna uma crise do regime ou do Estado. A crise pode ser "devido ao grande número de descontentes, difíceis de domar pela sua mera quantidade e pela simultânea, mas mecanicamente simultânea, manifestação de descontentamento em toda a área da nação" ( $Q 2, \$ 75$, p. 234). Nesses casos a solução "tende apenas a refazer a cobertura política externa de um conteúdo social que não passa por uma crise constitucional real” (Q2, \$75, p. 234).

\section{O laboratório francês}

Essa distinção entre crise parlamentar e crise do Estado é importante para o desenvolvimento da reflexão no interior dos Quaderni. As formulações apresentadas no $₫ 75$ do Quaderno 2 e no $\$ 23$ do Quaderno 13, ganharam maior concretude nas anotaçôes de Gramsci a respeito da vida nacional francesa, as quais culminaram no $₫ 37$ do Quaderno 13. Gramsci já havia indicado que o caso francês era de grande importância devido ao seu caráter exemplar e que os "partidos franceses" eram um campo muito rico para a pesquisa sobre a crise de hegemonia: "todos eles são documentos mumificados e anacrônicos, documentos histórico-políticos das diferentes fases da história passada francesa, dos quais repetem a terminologia antiga." ( $\mathrm{Q} 13, \$ 23$, p. 1604). A França apresentava-se, assim, como o laboratório escolhido por Gramsci para testar suas hipóteses.

$\mathrm{O} \$ 37$ do Quaderno 13 é um texto mais orgânico do que aquele do $₫ 23$. Ele reúne anotações presentes todas no Primo quaderno, escritas entre julho de 1929 e março de 1930, e organizadas em torno de um conjunto bastante preciso de temas: 
a Action Française de Charles Maurras, suas relações com o Vaticano e a crise parlamentar de 1925-1926 ${ }^{28}$. Em sua segunda redação essas notas foram reagrupadas com o título "Note sulla vita nazionale francese" indicando que a análise do dissídio entre os monarquistas católicos e o papado receberia um enquadramento mais amplo.

Nesse estudo Gramsci adotou uma periodização de longa duração, apresentada no $\$ 17$ do Quaderno 13, a qual, partindo da Revolução Francesa, via nos acontecimentos da Comuna de Paris de 1871 a exaustão histórica de todos os germes nascidos em $1789^{29}$. A periodização que organizava a pesquisa gramsciana questionava aquela adotada por Benedetto Croce em sua Storia d'Europa nel secolo decimonono, que começava sua narrativa com a derrota de Napoleão Bonaparte e a restauração (Croce, 1999 [1932]). Em um conjunto de notas inscritas no Quaderno 8 e depois transcritas para o Quaderno 10, Gramsci questionou a narrativa croceana e evidenciou o caráter político desta:

Mas o século XIX existe sem a Revolução Francesa e as guerras napoleônicas? Os eventos tratados por Croce podem ser organicamente concebidos sem esses precedentes? O livro de Croce é um tratado de revoluções passivas, para usar a expressão de Cuoco, que não podem ser justificadas e compreendidas sem a Revolução Francesa, que foi um evento europeu e mundial, não apenas francês $(\mathrm{Q} 8, \$ 236, \mathrm{p} .1088)^{30}$.

28. Nesse conjunto de notas, as fontes que Gramsci tinha em mãos são poucas e conhecidas. A ruptura do Vaticano com a Action Française chamou-lhe a atenção muito cedo na prisão. Em 3 de outubro de 1927 solicitou a Tania o livro de Charles Maurras e Leon Daudet, L'Action Française et le Vatican (L, p. 124) e no dia 14 de novembro lhe informou que o livro havia chegado (L, p. 132). Mais tarde, em carta a Giuseppe Berti sintetizou as ideias presentes nesse livro e apontou outras fontes. Com relação ao livro citado, revelou seu interesse na iniciativa de formação de um "partito cattolico democratico" por parte do Vaticano, um tema com evidentes repercussões na Itália, onde após a concordata os católicos havia entrado oficialmente na arena política (L. 153). As outras fontes comentadas nessa carta são a Storia della terza repubblica: La Francia dal settembre 1870 al 1926, de Alessandro Zévaès, considerado "superficialissimo ma divertente", e La Francia contemporanea, de Robert Michels, "una trufa libraia” (L. 153-154). Além do livro de Maurras e Daudet, Gramsci citou no $\$ 48$ do Primo quaderno dois artigos presentes em uma edição do Alamanach de L'Action Française que possuía na prisão, um de Leon Daudet (1929) e outro de Jacques Bainville (1929). Deve se destacar, entretanto, que no cárcere de Turi Gramsci tinha acesso muito restrito à imprensa e somente entre outubro de 1931 e a primavera de 1932 pôde ter acesso ao Corriere della Sera. A maior parte das informações que recebia da França eram de segunda mão e provinham de revistas como Nuova antologia, L'Italia letteraria e Critica fascista. Sobre as fontes francesas de Gramsci ver Gervasoni (1998).

29. "Realmente as contradições internas da estrutura social francesa que se desenvolvem depois de 1789 encontram sua relativa composição apenas com a terceira república e a França tem 60 anos de vida política equilibrada depois de 80 anos de reviravoltas em ondas sempre mais longas: 89-94-99-18041815-1830-1848-1870" (Q 13, \$17, p. 1582).

30. Sobre o caráter politico da crítica gramsciana a Croce, ver Frosini (2015). 
Essa nota foi escrita em maio de 1932 quase ao mesmo tempo que Gramsci redigia a citada nota do Quaderno 9, na qual se discutiam as interpretações do Rissorgimento. Nesse último parágrafo, era feita uma referência implícita à Storia d'Europa. Segundo Gramsci, embora o crítico abruzês, superasse Adolfo Omodeo, o qual circunscrevia a história do liberalismo exclusivamente na península e parecia afirmar a primazia de um "liberalismo italiano", a Storia croceana suprimia da narrativa o momento da revolução e das guerras, ou seja, o jacobinismo e o próprio ato de nascimento e difusão da democracia parlamentar na Europa continental ( Q 9, § 89, p. 1153). Por fim, a exclusão da Revolução Francesa da narrativa histórica croceana foi criticada no Quaderno 10, em um parágrafo coetâneo àqueles dois já citados. Segundo Gramsci a periodização levada a cabo por Croce era o resultado de um "hegelismo degenerado e mutilado, porque sua preocupação fundamental é um medo pânico dos movimentos jacobinos, de toda intervenção ativa das grandes massas populares como fator de progresso histórico" ( $\mathrm{Q} 10 / \mathrm{I}, \$ 6, \mathrm{p} .1220$ ).

Contrariando essa periodização croceana, a qual tinha por objetivo expurgar o momento da revolução da narrativa e resumir a história da França ao período da restauração, a parábola da crise descrita por Gramsci tinha início "na fase ativa da Revolução francesa”, na qual o desenvolvimento do "jacobinismo (de conteúdo) e da fórmula da revolução permanente":

[...] encontrou seu "aperfeiçoamento" jurídico-constitucional no regime parlamentar, que realiza, no período mais rico das energias "privadas" na sociedade, a permanente hegemonia da classe urbana sobre toda a população, na forma hegeliana de governo com o consentimento permanentemente organizado (mas a organização do consentimento é deixada para a iniciativa privada, é portanto de natureza moral ou ética, porque o consentimento é dado "voluntariamente" de uma forma ou de outra) (e 13, §37, p. 1636).

As formas institucionais e politicas que esse processo assumiu foram variadas. Em um arco de tempo que se prolongou entre 1789-1893 e 1871-1914, ocorreram ondas de revolução e repressão, expansão e retração do sufrágio, constitucionalização e desconstitucionalização da política, distribuição e redistribuição dos poderes no interior do aparelho estatal. As diferentes formas político-institucionais francesas foram descritas de modo sumário por Gramsci, mas dada a escassez de fontes adequadas é surpreendentemente precisa. Tal descrição tinha por objetivo ilustrar uma tese fundamental: a hegemonia não é própria de uma única forma institucional. Ela pode se realizar por meio de várias formas. As recorrentes mudanças constitucionais ocorridas nesse período não abalaram o "exercício 'normal' da hegemonia no terreno que se tornou o clássico do regime parlamentar”. Este permaneceu de pé, 
[...] caracterizado pela combinação de força e consenso que são equilibrados de várias maneiras, sem que a força supere muito o consenso, mesmo tentando obter que essa força apareça apoiada pelo consentimento da maioria, expressa pelos chamados órgãos da opinião pública - jornais e associações - que, portanto, em certas situações, são multiplicados artificialmente (Q 13, §37, p. 1638).

Embora as instituições parlamentares continuassem funcionando no período do pós-guerra, "o aparato hegemônico se fissura e o exercício da hegemonia se torna permanentemente difícil e aleatório". Percebida por meio de seus efeitos mais superficiais, essa dificuldade de exercer de modo "normal" a hegemonia por meio do regime parlamentar era denominada pela opinião pública da época, como visto, de "crise do princípio de autoridade" ou de "dissolução do regime parlamentar". Os efeitos mais notáveis dessa crise eram a:

[...] dificuldade crescente na formação de governos e na crescente instabilidade dos próprios governos, a qual tem sua origem imediata na multiplicação dos partidos parlamentares e nas crises internas permanentes de cada um desses partidos (ou seja, dentro de cada partido verifica-se aquilo que se verifica em todo o parlamento: dificuldade de governo e instabilidade da governação da direção) (Q 13, §37, p. 1639).

Gramsci parece dar grande importância à multiplicação dos partidos políticos eà emergência de um grande número de soluções. No interior dos partidos, cada fração acredita ter em mãos a receita que pode deter o enfraquecimento da agremiação. No parlamento, cada partido está convencido de que pode formar sob sua direção uma nova e estável maioria. As formas mais mórbidas da política manifestam-se agudamente - "negociações capciosas e minuciosas", "escandalosas", "insídia e perfídia” (Q $13, \S 37$, p. 1639). Mas para a opinião pública prevaleceriam as ações vistas como “personalistas". A crise parece ser o momento no qual as personalidades políticas individuais, frequentemente demagógicas, emergem ou, pelo menos, se tornam mais visíveis. Embora o sardo não fizesse menção ao fascismo nesse parágrafo, é bastante evidente que a situação italiana reverberava nos temas de análise.

Em um certo ponto do texto Gramsci escreveu: "La crisi in Francia" e a partir daí seu discurso político ganhou novos tons. Nas páginas seguintes, em vez de uma análise generalizante da crise política no pós-guerra, é possível encontrar uma sutil análise das relações de forças na França. Gramsci passou então a destacar a lentidão do desenvolvimento da crise nesse país, tornando o argumento precedentemente apresentado mais matizado e sutil. A multiplicidade de partidos existentes, em vez de ser um indicativo da crise, passou a ser vista como "muito útil” para a formação 
e seleção de um "um número grande de hábeis homens de governo" ( $13, \$ 37$, p. 1640). O grande número de políticos experientes, a concentração de intelectuais em instituições e revistas, a tradição e a homogeneidade da burocracia militar e civil, tudo isso contribuía para tornar a hegemonia burguesa "muito forte" e com "muitas reservas" ( $\mathrm{Q} 13, \$ 37, \mathrm{p} .1640)$.

A conclusão de Gramsci era a de que "a guerra não debilitou mas reforçou a hegemonia" e mesmo depois da guerra as "lutas internas [...] não tiveram, por isso, grande aspereza" ( $\mathrm{Q} 13, \$ 37$, pp. 1640-1641). O argumento reforçava a distinção entre a crise de hegemonia e a crise parlamentar. Esta última, apesar de ser endêmica na França, "não teve até agora um caráter radical, nem colocou em jogo questões intangíveis" (Q 13, \$37, p. 1641). Embora ocorressem deslocamentos políticos importantes os representados encontravam rapidamente novos representantes e novos equilíbrios entre os partidos eram formados, a crise parlamentar não se traduzia, desse modo, em uma separação radical entre governantes e governados.

Na análise gramsciana, até mesmo a crise parlamentar de 1925 e 1926, quando a Action Française achou que era chegada sua hora de assumir o poder e anunciou seu futuro governo, esteve muito longe de representar uma crise de hegemonia. A ruptura que o Vaticano promoveu com Maurras implicou em um afastamento das grandes massas nacionais dos monarquistas clericais por ele liderados. $\mathrm{O}$ sonho reacionário de que o regime republicano pudesse cair em meio de uma crise parlamentar era, segundo Gramsci, uma "estupidez". Em meio à crise, o sistema partidário continuou a funcionar as usual:

No momento decisivo, vemos que as grandes massas de energia que entraram na crise não são despejadas em reservatórios criados artificialmente, mas seguem os caminhos realmente traçados pela política real anterior, movem-se de acordo com os partidos que sempre estiveram ativos, ou mesmo que nasceram como cogumelos no próprio chão da crise ( $\mathrm{Q} 13, \S 37$, p. 1647).

\section{Conclusões}

Ao enfatizar caráter superficial das crises parlamentares, em especial, daquela francesa de 1925-1926, Gramsci destacou a distinção entre esta e a crise de hegemonia. Desse modo, afastou-se da literatura conservadora e fascista que considerava a crise um fenômeno inerente às instituições políticas representativas em geral e, em particular, àquela combinação específica de sufrágio ampliado e parlamentarismo que caracterizava as democracias modernas. Concebendo a crise política em seu sentido mais forte como crise de hegemonia, sua análise se deslocou da pequena política, ou seja, daquela caracterizada pelas "lutas de predomínio entre as diversas frações 
de uma mesma classe política", para a grande política. Com isso a investigação era transferida da arena parlamentar para a sociedade civil.

Gramsci acertava as contas com as interpretações fascistas. Comentando no Quaderno 15 um artigo de Sergio Panunzio publicado na revista Gerarchia, no qual era discutido o fim do parlamentarismo, ele criticou o caráter formalista do argumento de Panunzio, típico "dos velhos constitucionalistas", mas reteve o tema: a dificuldade de construir uma direção política permanente em um regime parlamentar. Para tratar o tema de modo apropriado, escreveu nos Quaderni, seria necessário estudar a multiplicação dos partidos políticos, as razões da dificuldade para formar uma maioria parlamentar e a decadência dos grandes partidos tradicionais. Do ponto de vista de Panunzio, a análise desses fenômenos e da crise seria "puramente parlamentar" e nesse sentido retomava muitos dos argumentos da Destra storica acima apresentados. $\mathrm{O}$ autor dos Quaderni apontava, entretanto, para outra direção, na qual seria possível identificar "mutações radiciais que ocorreram na própria sociedade" (Q 15, \$47, p. 1807).

Para compreender a crise real e "a origem da decadência dos regimes parlamentares" seria necessário concentrar-se nas transformações que teriam ocorrido na sociedade civil. Gramsci considerava que a pesquisa deveria dar importância ao "fenômeno sindical". Não ao sindicalismo corporativo de Panunzio e do fascismo, ou seja, não o "associativismo de todos os grupos e por qualquer fim", e sim "dos elementos sociais recém-formados, que anteriormente não tinham 'nada a dizer' e que simplesmente unindo-se mudavam a estrutura política da sociedade" (Q 15, \$ 47, p. 1808). Era na emergência de novos grupos sociais, das classes trabalhadoras, na vida política nacional e na incapacidade das classes dirigentes tradicionais absorvê-las nessa vida, que poderia ser desvendado o segredo da crise.

Se a crise não era decorrência das instituições parlamentares, sua solução não poderia ocorrer por meio da supressão dessas instituições, como imaginava o fascismo. O "desaparecimento dos partidos políticos" e o "esvaziamento do Parlamento" promovido pelo regime de Mussolini era uma "solução 'burocrática', a qual mascarava que "os partidos são substituídos por camarilhas e influências pessoais não confessáveis". A eliminação dos partidos implicava na supressão daqueles órgãos responsáveis não apenas pela elaboração das "direções políticas", tão desejados por Panunzio, como também, dos meios capazes de formar e educar "os homens de modo a aplicá-las", as classes dirigentes (Q 15, §48, p. 1809).

A resposta à qual o fascismo não conseguia chegar havia sido apresentada por Gramsci no $\$ 49$ do Quaderno $14^{31}$. Comentando a oposição da burocracia estatal ao

31. Os $₫ 47$ e 48 do Quaderno 15 foram escritos em maio de 1933, enquanto o $₫ 49$ do Quaderno 14 é de fevereiro do mesmo ano. 
regime parlamentar, considerado um obstáculo ao bom funcionamento da administração, Gramsci destacou que uma coisa era reconhecer a ineficiência e a inadequação do parlamentarismo e outra, bem diferente, era desejar o restabelecimento de um poder burocrático que operasse sem nenhum contrapeso ou controle. A solução apresentada por Gramsci como uma hipótese de trabalho questionava a identificação entre regime parlamentar e regime representativo, ponto de convergência entre liberais, conservadores e fascistas. A maneira de apresentar a questão era cuidadosa: "É preciso ver se o parlamentarismo e o regime representativo se identificam e se uma solução diferente do parlamentarismo e do regime burocrático não é possível, com um novo tipo de regime" ( $\mathrm{Q} 14, \$ 49$, p. 1708).

A ideia de um novo tipo de regime representativo não foi desenvolvida nos Quaderni e permaneceu como hipótese. Mas se a crise era uma crise de hegemonia, caracterizada pela separação entre governantes e governados, dirigentes e dirigidos, compreende-se o sentido da solução. Ela não poderia resumir-se à exposição de uma reforma institucional, como aquelas que a literatura da Destra storica havia tantas vezes apresentado no final do século XIX. A solução só poderia estar em uma nova relação entre representantes e representados. Uma relação que superasse os limites que a teoria elitista havia imposto.

Referências Bibliográficas

Albertoni, Ettore A. (1985), Dottrina della clase politica e teoria delle elites. Milano, Giuffrè. Bainville, Jacques. (1929) “Comment finissent les régimes parlementaires”. Almanach de L'Action Française, 21: 51-58.

Bettoni, Fabio. (1984), “Gramsci e Michels: Un itinerario critico”. In: Furiozzi, G. B. (org.). Roberto Michels tra politica e sociologia. Firenze, Centro Editoriale Toscano, pp. 195-251.

Cammarano, Fulvio. (1999), Storia politica della Italia liberale. Bari, Laterza.

Caroncini, Alberto. (1912), "Il libro di Pasquale Turiello". La Voce, a. IV (12): 779-780.

Cosprto, Giuseppe. (2011), "Verso l'edizione critica e integrale dei 'Quaderni del carcere”. Studi Storici, 52 (4): 881-904.

Croce, Benedetto. (1923), "Rivista bibliografica”. La Critica: Rivista di Letteratura, Storia e Filosofia, 21: 374-378.

Croce, Benedetto. (1999 [1932]), Storia d'Europa nel secolo decimonono: a cura di Giuseppe Galasso. Milão, Adelphi.

Croce, Benedetto. (2004 [1928]), Storia d'Italia dal 1871 al 1915. Napoli, Bibliopolis.

D’Orsi, Angelo. (2002), Allievi emaestri: l'Università di Torino nell'Otto-Novecento. Torino, Celid.

D'Orsi, Angelo. (2011), L'Italia delle idee: il pensiero politico in un secolo e mezzo di storia. Milano, Bruno Mondadori. 
Daudet, Leon. (1929), “L'Action Française quotidienne a vingt anes". Almanach de L'Action Française, 21: 51-58.

Filıppini, Michele. (2015) Una politica di massa: Antonio Gramsci ela rivoluzione della società. Roma, Carocci

Filippini, Michele. (2017), “Max Weber”. In: PAssos, Rodrigo Duarte Fernandes dos \& Areco, Sabrina. Gramsci e seus contemporâneos. Marilia/São Paulo, Oficina Universitária/ Cultura Acadêmica, pp. 115-144.

Francioni, Gianni. (2009) "Quaderno 2 (1929-1933). Nota introduttiva”. In: Gramsci, Antonio.Quaderni del carcere: edizione anastatica dei manoscritti. Roma/Cagliari, Biblioteca Treccani/L'Unione sarda.

Frosini, Fabio. (2015), “Sulle 'spie’ dei 'Quaderni del carcere’”. International Gramsci Journal, v. 1, n. 43-65.

Gervasoni, Marco. (1998), Antonio Gramsci e la Francia: dal mito della modernità alla "scienza della politica”. Milano, Unicolpi.

Gobetti, Piero. (1924), “Un conservatore galantuomo”. La Rivoluzione Liberale, 18: 3.

Gobetti, Piero. (1922), "Manifesto”. La Rivoluzione Liberale, 1: 1-2.

Gramsci, Antonio. (1966), Socialismo e fascismo: L’Ordine Nuovo, 1921-1922. Torino, Giulio Einaudi.

Gramsci, Antonio. (1977), Quaderni del carcere: edizione a cura di Valentino Gerratana. Torino, Enaudi.

GramsCI, Antonio. (1987), La costruzione del Partito comunista, 1923-1926. Torino, Einaudi GramsCi, Antonio. (1982), La cittá futura, 1917-1918: a cura di Sergio Caprioglio. Torino, Einaudi. Gramsci, Antonio. (1996), Lettere dal carcere: a cura di Antonio Santucci. Palermo, Sellerio. Maine, Henry Sumner. (1885), Popular government. Londres, John Murray.

Michels, Robert. (1927), Corso di sociologia politica. Milano, S. A. Instituto Editoriale Scientifico.

Minghetti, Marco. (1881), I partiti politici e la ingerenza loro nella giustizia e nell'amministrazione. Bolonha, Nicola Zanichelli.

MosCA, Gaetano. (1982 [1884]), Scritti politici: a cura di Giorgio Sola. Torino, Utet.

PAReto, Vilfredo. (1988 [1923]), Trattato di sociologia generale: edizione critica a cura di Giovanni Busino. Torino, Utet.

Prezzolini, Giuseppe. (1960), “L'aristocrazia dei briganti”. In: Frigesi, Delia. La cultura italiana del '900 attravverso le riviste. Torino, Giulio Einaudi, v, I, pp. 455-460.

PRINS, Adoiphe. (1884), La démocratie et le regime parlementaire Bruxelas, Murquardt.

Scherer, Edmond. (1884), La démocratie et la France: études. Paris, Librairie Nouvelle.

Sgambatti, Valeria. (1977), “Per un'analisi del rapporto tra Gramsci e gli èlitisti”. In: Ferri, Franco (org.). Politica e storia in Gramsci. Roma, Riuniti, v. II. pp. 606-616.

Sola, Giorgio. (1994), Mosca. Bari, Laterza. 
Syme, David. (1882), Rerpesentative government in England: its faults and failures. Londres, Kegan Paul \& Trench.

Turiello, Pasquale. (1882), Governo e governati in Italia. Bolonha, Nicola Zanichelli.

Un Deputato [Sidney Sonnino]. (1897), “Torniamo allo Statuto”. Nuova Antologia, v. LXviI, fasc. I: 9-28, $1^{\circ}$ gen.

VACCA, Giuseppe. (2017), Modernità alternative: il Novecento di Antonio Gramsci. Torino, Einaudi.

\section{Resumo}

Classe politica e crise da democracia na crítica de Antonio Gramsci

No início dos anos 1880 um novo gênero de literatura política começou a ganhar vigor e a expandir-se, a análise crítica das democracias parlamentares existentes. Na Itália, esse gênero teve uma importante expressão na obra de Gaetano Mosca. Antonio Gramsci confrontará essa literatura, preocupado com sua reapropriação e revalorização no debate político a partir do imediato pré-guerra, quando a crise da democracia liberal assumiu contornos mais fortes. $\mathrm{O}$ artigo mostra como Gramsci traduz o conceito mosquiano de classe política como "a categoria intelectual do grupo social dominante" e integra-o à sua reflexão sobre os partidos políticos. Desse modo pode interpretar a crise do regime parlamentar como uma crise marcada pela decomposição dessa "categoria intelectual" e pela perda de sua capacidade dirigente. Aquilo que na teoria elitista aparecia como decomposição do princípio de autoridade era interpretada como uma crise de hegemonia, crise do Estado em seu conjunto, da qual o afastamento entre governantes e governados seria a manifestação mais evidente. Na seção conclusiva, apresenta-se a hipótese aventada nos Quaderni del carcere de um regime representativo não parlamentar.

Palavras-chave: Crise da democracia; Elitismo; Antonio Gramsci; Itália.

\section{Abstract}

Political class and crisis of democracy in Gramsci's critical analysis

From the early 1880 s on a new genre of political literature began to take hold and to expand in Italy: the critical analysis of the existing parliamentary democracies. This literary genre had an important expression in the work of Gaetano Mosca. Decades later, during the fascist era, Antonio Gramsci confront this literature in his Prison Notebooks, specially by reappropriating and revaluating the political debate of the immediate prewar period, when the crisis of liberal democracy took on stronger contours. The present article shows how Gramsci translates the Moschian concept of political class as "the intellectual category of the dominant social group" and integrates it to his own discussion about political parties in the prison writings. Gramsci interpretates the parliamentary crisis as a decomposition of this particular "intellectual category" and the loss of its leading capacity. What appeared as a decomposition of the principle of authority in the elitist theory is now discussed as a crisis of hegemony, a crisis of the State as a whole, 
from which the separation between rulers and ruled would be the most evident manifestation. In the concluding section is discussed the hypothesis proposed in the Quaderni del carcere of a non-parliamentary representative regime.

Keywords: Crisis of democracy; Elitism; Antonio Gramsci; Italy.

Texto recebido em 2/5/2019 e aprovado em 7/5/2019.

DOI: $10.11606 / 0103-2070 . t s .2019 .157651$

Alvaro Bianchi é diretor do Instituto de Filosofia e Ciências Humanas (IFCH) da Unicamp e autor de, entre outros livros, O laboratório de Gramsci: filosofia, história e politica (Porto Alegre, Zouk, 2018).E-mail: abianchi@unicamp.br. 